\title{
Critical Geographies of Sport: Space, power and sport in global
}

perspective, edited by N. Koch, Oxon, Routledge, 2017, £90.00 (hardback), 272 pp., ISBN 9781138927124

Catherine Waite

Environmental and Geographical Sciences University of Northampton

Since the publication John Bale's Sports Geography (2003) nearly 25 years ago there have been sporadic instances of geographers undertaking research on sport. However, in recent years there has been increasing attention given to the geographies of sport. This book therefore offers a timely contribution, and welcome addition, to a limited literature that offers a specifically geographical approach to the study of sport. It is a well-written and accessible volume that will be of interest to those already engaging with literature in this field or those who are exploring it for the first time.

The book comprises an edited collection of empirically grounded chapters which cover a wide range of sports, contexts and approaches. Despite this variety, the book as a whole is unified by its clear focus on space and power. There is clear recognition throughout the contributions that sport is inherently political and that there are inescapable power relations in all types of sport. These are explored using a spatial focus and so effectively demonstrate the scope and value of a geographical approach to studies of sport.

Natalie Koch, the editor of this volume, identifies herself as being a political geographer and these interests are evident throughout this book. All the chapters sit at the intersection of geography, politics and sport, but do so through a variety of approaches. Thinking about the spatial extent of this book, the case studies span Europe, the Americas and Asia and include countries such 
as the UK, Finland, South Korea, Turkmenistan and Israel. There are also a number of chapters that consider the USA, so whilst there is evidence of globally dispersed research, there are other notable countries that are absent, including African nations, as well as other regions of the world. However, this is not just a gap in this text; it is reflective of the state of burgeoning critical geography research on sport more generally: an issue which is highlighted in the editor's introduction.

Through the empirical examples, we see how the relationship between sport and politics plays out in local, regional, national and international contexts. At the national scale, there are discussions regarding nation building and nationalism in chapters by Horák, Koch and Crampsie for instance. Whilst at the local scale, there is consideration of topics including integration (e.g. Conner), belonging (e.g. Nelson) and citizenship (e.g. Cook, Shaw and Simpson). These topics are at the heart of political and geographical research, but these case studies all show how sport is an integral part of how they are executed and experienced.

Cutting across these multiple spatial scales, this book importantly highlights the significance of considering identity and aspects of social difference in the context of sport. It is demonstrated how sport can be both unifying and divisive along lines of social difference. Both in and through sport, the chapters in the volume show how identity can be constructed and contested. By thinking about the linkages between sport and society, and consequently politics and power relations, critical consideration is given to gender, ethnicity, religion, race, age and class, and how these are manifested in sporting contexts.

Whilst the focus of this book is on space, it also presents case studies that utilise a range of timescales. The empirical chapters present historical examples (e.g. 
Shihade; Gardener), contemporary studies (e.g. Tynkkynen; Woo Lee), and chapters that include both within their discussions (e.g. Raento; Koch). This variety is complemented by studies that consider long-term trends and changes as well as those that highlight the importance of studying the micro-scale; everyday activities that might otherwise be considered banal or mundane. Yet, what these chapters effectively show is the significant role that sport plays at such temporal scales when considering topics such as integration, belonging and social justice (e.g. Nelson; Wise).

A further sub-theme that runs throughout the text relates to the environment and associated geopolitics. At the outset, it is stated that this book aims to "stimulate geographers' interest in the wider field of sports studies"; several of the empirical contributions make reference to the relationship between sport and environmental issues, and in doing so introduce another area where geographers could make a fruitful contribution to this field. Chapters by Horák and Tynkkynen for instance consider the relationship between fossil fuels, power, politics and sport. In proposing an agenda for future geographic research on sport, Jansson and Koch suggest further research is required on the "environmental impacts of our sporting activities" (p. 244) as well as recognising the potential of a critical geography approach to investigating ecological privilege in sport.

Overall, this is a valuable text that I would recommend to geographers and nongeographers alike. The collection successfully achieves its aim "to showcase the merits of a deeply geographic approach to the study of sport" (p1). It is therefore deserving of a wider audience than those already persuaded by the usefulness of a geographic approach to studying sport. It not only attempts to begin to overcome the persisting absence of sport as a subject of geographical 
study, but in doing so the authors make helpful suggestions regarding future possibilities for geographical studies of sport. Such a suggestion includes using sport as a lens to explore and reimagine the gender binary and propose more inclusive alternatives. Likewise, to advance the political studies of sport that this volume contributes to, it is suggested that there is potential for further critical consideration of the impacts of neoliberalism and globalisation, particularly at the grassroots level, where sport may provide an effective space for the resistance of some of the more undesirable impacts of these processes. Therefore, for non-geographers, this text provides a useful insight into what geography can offer as a disciplinary perspective and how core geographical concepts including space, place and scale can guide and frame studies of sport.

\section{References}

Bale, J. (2003). Sports Geography. $2^{\text {nd }}$ Ed. London: Routledge. 